\title{
The Significance of 4D Ultrasonography in Fetal Anomaly Screening
}

\author{
Demet Aydoğan Kırmızı \\ Republic of Turkey, Denizli Çal State Hospital Obstetrics and Gynecology Clinic, Denizli, Turkey
}

\begin{abstract}
Ultrasonography has been a reliable diagnostic tool used for years in fetal anomaly screening. Along with technological improvements, the image quality of ultrasound devices has also increased. Four-dimensional (4D) ultrasound with real time imaging capability is the latest technological tool in this area. Today, its use in perinatologic screening of fetal ano malies is becoming widespread This situation has opened the debate on the diagnostic value of 4D ultrasound in fetal evaluation. 4D ultrasound when performed in experienced hands provides more detailed information on organ functions, fetal anomalies, and understanding of movement and behavioral characteristics. In contrast, conventional 2D ultrasound maintains an indispensable position in the evaluation of fetuses. In the literature, the superiority of $4 \mathrm{D}$ to $2 \mathrm{D}$ has not been shown. However, diagnostic accuracy is expected to increase when the techniques are used together. A general evaluation was made in our article and the significance of the two ultrasound technologies in detecting fetal anomalies were compared.
\end{abstract}

Key Words: Fetal anomaly, 4D ultrasound, pregnancy

\section{Introduction}

Diagnosis of fetal anomalies is important in detecting fetal/maternal problems that may occur during and after pregnancy. Therefore fetal imaging is of great importance for obstetricians. The efficacy of $2 \mathrm{D}$ and $4 \mathrm{D}$ ultrasound in diagnosis has been evaluated by several studies and the use of $4 \mathrm{D}$ ultrasound in routine practice has begun to be investigated. In our study, literature review was conducted and evaluations related to the topic were presented.

Since the early 1970s, ultrasound devices have been serving modern medicine and they have become an indispensable part of pregnancy monitoring. Parallel to the advances in computer technology and developments in industry, the image quality of ultrasound devices has also improved. The reliability of ultrasound has long been known. No important side effects were observed in the studies. Although some side effects of ultrasound have previously been reported in animal studies, these results have not been shown by other groups. Particularly in 3 dimensional (3D) and 4 dimensional (4D) ultrasound, the thermal index and mechanical index are automatically controlled and the amount of energy transfered to the tissue during the ultrasound examination is kept to a minimum
$(1,2)$.

The image quality of the state-of-the-art technology, 4D ultrasound, is significantly better than the standard 2 dimensional (2D) ultrasound, in a way that the details of the tissue are almost as distinguishable as the Magnetic Resonance (MR) images. 4D ultrasound being the latest technological development allows 3D (spatial) view of width, length and depth dimensions in real time on a monitor. The spread of this technology initiated the discussion on how necessary it is in following up the pregnancy. It has been shown that 3D/4D ultrasound is particularly useful for improving the analyses of some detected anomalies using 2D ultrasound. Kurjak et al. (3) has shown that structural and functional fetal facial evaluation is superior with $3 \mathrm{D} / 4 \mathrm{D}$ ultrasound compared to 2D. In addition to facial evaluation, studies have reported that cleft palate, lip $(4,5)$, neural tube defects, skeletal anomalies (6) and brain defects can be detected.

During the development of the $3 \mathrm{D} / 4 \mathrm{D}$ ultrasonography, degradation in image quality and time loss in the processing of the images, has been improved by developing more advanced probes and image processing pipelines which in time transformed the ultrasound to be an excellent diagnostic tool. Many clinicians were initially skeptical about their clinical use, but the feasibility 
of the technique over time was accepted. The First World Congress for 3D ultrasound was held in 1997 in Mainz, Germany. In 2005, the American Ultrasound Society announced that 3D ultrasound would be effective in many cases, but stated that the necessary areas of use should be well identified (7).

In a study done on 99 fetuses where fetuses were first evaluated with $3 \mathrm{D} / 4 \mathrm{D}$ and later with $2 \mathrm{D}$ ultrasound; 54 normal and 45 anomalous fetuses (82 anomalies) were detected by 2D ultrasonography. 2D ultrasonography identified 6 more anomalies compared to 3D/4D (VSD, IVC blockage, Fallot tetrology, renal anomaly, cystic adenomatoid malformation). A fetal hemivertabra and a small occipital encephalocele existing in one of the fetuses were not observed with either of the ultrasonografic techniques. Sensitivity was $96 \%$ in $2 \mathrm{D}$ and $92 \%$ in $3 \mathrm{D} / 4 \mathrm{D}$ when compared with postnatal diagnosis; Specificity was $73 \%$ in $2 \mathrm{D}$ and $76 \%$ in $3 \mathrm{D} / 4 \mathrm{D}$. No statistically significant difference was found (8).

Öcal et al. (9) in 2015 studied 1379 pregnant women with 2D and 4D ultrasound, authors detected 194 anomalies among 174 pregnancies, and $2 \mathrm{D}$ ultrasonography was found to be superior in detecting anomalies compared to $4 \mathrm{D}(\mathrm{p}<0.001)$. 4D ultrasonography was found to be better for detecting anomalies associated with fetal face, extremity, spine and abdomen wall, and it has been reported that half of the anomalies and 15\% of all cases have a better quality image. In another study involving 204 patients, 3D ultrasonography showed a $62 \%$ advantage in showing fetal defects; $36 \%$ of the patients had the same information in $2 \mathrm{D}$ ultrasonography and $2 \%$ of the patients were found have disadvantages when imaged with $3 \mathrm{D}$ (10). In another study of 159 pregnancies in uncomplicated 12 to 13 weeks gestations, fetal anatomy was evaluated with $2 \mathrm{D}$ ultrasound, followed by 3D analysis of all fetuses. Complete anatomy was obtained $93.7 \%$ with $2 \mathrm{D}$ imaging and $80.5 \%$ with 3D (11). All kinds of anatomic evaluation on the fetus by $3 \mathrm{D} / 4 \mathrm{D}$ ultrasonography: morphometry, volumetry and functional analyzes were performed. 3D/4D provided many advantages in US fetal imaging; also contributed to improve the accuracy of $2 \mathrm{D}$ fetal screening (12).

Another discussion is that in the presence of maternal obesity, the detection of anomaly by the image provided by $4 \mathrm{D}$ drops the sensitivity down to $25 \%$ with the increase in obesity (13). Studies carried out on 11.000 pregnant women between 18-24 weeks of gestation indicate that with increasing obesity sensitivity obtained with
3D/4D images decreases. Presence of obesity has variable sensitivity between $34 \%$ and $60 \%$ in $2 \mathrm{D}$ ultrasonography as well. Andonotopo et al., (14) in their study investigating 50 fetuses with intrauterin growth restricted (IUGR) and 50 fetuses with normal growth using 3D/4D ultrasonography reported completely different movement patterns and in IUGR fetuses decrease movement, count, type patterns; hand to head movement, hand to face movement, retroflexion movement in the face were detected. It is stated that, better information is obtained before birth. By 4D ultrasonography, fetal behavior characteristics of fetuses with IUGR could be determined. However, the benefit of $4 \mathrm{D}$ in the cases where intrauterine treatment is not possible or will not change is still controversial.

Sonography is an operator dependent imaging modality. It may be difficult to generalize the obtained outcomes. As a result of the studies made so far, it is shown that in experienced hands, 4D technology enables the detection anomalies and provides quality fetal images; however, its routine practice instead of $2 \mathrm{D}$ is not thought to be plausible (7).

To conclude, 2D ultrasound is an integral component of $3 \mathrm{D} / 4 \mathrm{D}$ technology and $3 \mathrm{D} / 4 \mathrm{D}$ ultrasound will not be able to take its place, but it can be stated that for perinatology, they provide significant additional benefits to $2 \mathrm{D}$. Beside this, the superiority of $4 \mathrm{D}$ ultrasound for the detection of movement and general surface anomalies is certain.

\section{References}

1. American Institute of Ultrasound in medicine. Acoustic output measurement standards for diagnostic ultrasound equipment. Laurel (MD): AIUM; 1998.

2. Stark CR, Orleans M, Haverkamp AD, Murphy J. Short- and long-term risks after exposure to diagnostic ultrasound in utero. Obstet Gynecol 1984; 63: 194-200.

3. Kurjak A, Azumendi G, Andonotopo W, Salihagic-Kadic A. Three- and four-dimensional ultrasonography for the structural and functional evaluation of the fetal face. Am J Obstet Gynecol 2007; 196: 16-28.

4. Pretorius DH, House M, Nelson TR, Hollenbach KA. Evaluation of normal and abnormal lips in fetuses: comparison between three- and two-dimensional sonography. AJR Am J Roentgenol 1995; 165: 1233-1237.

5. Tonni G, Centini G, Rosignoli L. Prenatal screening for fetal face and clefting in a 
prospective study on low-risk population: can 3and 4-dimensional ultrasound enhance visualization and detection rate? Oral Surg Oral Med Oral Pathol Oral Radiol Endod 2005; 100: 420-426.

6. Merz E, Welter C. 2D and 3D Ultrasound in the evaluation of normal and abnormal fetal anatomy in the second and third trimesters in a level III center. Ultraschall Med 2005; 26: 9-16.

7. Merz E, Abramowicz JS. 3D/4D ultrasound in prenatal diagnosis: is it time for routine use? Clin Obstet Gynecol 2012; 55: 336-351.

8. Gonçalves LF, Nien JK, Espinoza J, et al. What does 2-dimensional imaging add to 3 - and 4dimensional obstetric ultrasonography? J Ultrasound Med 2006; 25: 691-699.

9. Öcal DF, Nas T, Güler I. The place of fourdimensional ultrasound in evaluating fetal anomalies. Ir J Med Sci 2015; 184: 607-612.
10. Merz E, Bahlmann F, Weber G. Volume scanning in the evaluation of fetal malformations: a new dimension in prenatal diagnosis. Ultrasound Obstet Gynecol 1995; 5: 222-227.

11. Michailidis GD, Papageorgiou P, Economides DL. Assessment of fetal anatomy in the first trimester using two- and three-dimensional ultrasound. Br J Radiol 2002; 75: 215-219.

12. Yagel S, Cohen SM, Messing B, Valsky DV. Three-dimensional and four-dimensional ultrasound applications in fetal medicine. Curr Opin Obstet Gynecol 2009; 21: 167-174.

13. Dashe JS, McIntire DD, Twickler DM. Maternal obesity limits the ultrasound evaluation of fetal anatomy. J Ultrasound Med 2009; 28: 1025 1030 .

14. Andonotopo W, Kurjak A. The assessment of fetal behavior of growth restricted fetuses by 4D sonography. J Perinat Med 2006; 34(6): 471 478. 